\title{
MOHAMED Ahmed, Langues et identité. Les jeunes maghrébins de l'immigration
}

\section{Geneviève Vermès}

\section{(2) OpenEdition}

Édition électronique

URL : https://journals.openedition.org/remi/4072

DOI : $10.4000 /$ remi.4072

ISSN : $1777-5418$

Éditeur

Université de Poitiers

\section{Édition imprimée}

Date de publication : 1 décembre 2004

Pagination : 196-197

ISBN : 2-911627-38-5

ISSN : 0765-0752

\section{Référence électronique}

Geneviève Vermès, "MOHAMED Ahmed, Langues et identité. Les jeunes maghrébins de l'immigration ", Revue européenne des migrations internationales [En ligne], vol. 20 - n³ | 2004, mis en ligne le 25 septembre 2008, consulté le 16 avril 2022. URL : http://journals.openedition.org/remi/4072 ; DOI : https://doi.org/10.4000/remi.4072

Ce document a été généré automatiquement le 16 avril 2022.

(c) Université de Poitiers 


\title{
MOHAMED Ahmed, Langues et identité. Les jeunes maghrébins de l'immigration
}

\author{
Geneviève Vermès
}

\section{RÉFÉRENCE}

MOHAMED Ahmed, Langues et identité. Les jeunes maghrébins de l'immigration, Fontenay sous bois ; SIDES, Psychologie des dynamiques interculturelles, 2003, 210 p. ISBN :

2-8686-1120-6

1 Voici sur un thème classique, un ouvrage empirique de psychologie qui tient compte des apports des sciences sociales et présente des références bibliographiques certes un peu anciennes mais souvent méconnues des sociologues. Il est publié dans une collection dirigée par Geneviève Vinsonneau, spécialiste de Psychologie sociale dont on connaît et apprécie la qualité des recherches en psychologie interculturelle.

2 L'identité personnelle y est analysée cliniquement, et la langue est approchée comme marqueur d'identité et comme ressource identitaire dans un contexte de rapports sociaux inégalitaires et d'acculturation. Elle n'est pas pensée comme un élément essentialiste qui construirait l'individu ou/et structurerait sa pensée. La langue et la culture d'origine ici considérée comme bien approchée par les références à la religion musulmane y sont conçues comme organisateurs psychiques qui favorisent l'appropriation des repères d'évaluation et de la netteté des différents codes, la fermeté des défenses au stress d'acculturation. Ce n'est donc pas le rôle de l'appropriation cognitive de la langue maternelle qui est analysé mais son rôle affectif et psychosocial. Sous cet angle, les données psychologiques nous montrent que l'apprentissage de la langue et de la culture d'origine est un élément positif pour les jeunes Maghrébins. C'est vers un objectif de biculturalisme et de bilinguisme que l'auteur grâce à ses données nous conduit. Pour celui-ci, il ne s'agit pas tant de préserver la langue 
maternelle que d'assurer aux deux langues, l'arabe et le français un statut d'égalité symbolique permettant au jeune de vivre sans conflit, sans hiérarchie sa double appartenance avec un sentiment de sécurité, de continuité, de fermeté des défenses face à toute déculturation dans un respect des images de soi.

La perspective clinique de l'auteur nous ouvre sur des concepts que le sociologue abordera avec profit tels que l'élaboration psychique du processus identitaire, la nécessité d'une enveloppe culturelle, de renforcement narcissique.

4 Le corpus des données réduit malheureusement par des contraintes éditoriales explorent plusieurs techniques d'investigation : entretien semi-directif des jeunes et de leurs parents, tests projectifs, test «qui suis-je?». Ainsi se voient combinés questionnaire d'enquête et approche clinique; les attitudes et représentations des enseignants français vis à vis des ELCO sont aussi analysées. La méthodologie, fréquente en psychologie, compare deux populations quatre-vingt-dix jeunes de moins de onze ans et de onze à dix sept ans qui suivent des cours d'ELCO, et quatre-vingt-dix de même âge ne les suivant pas.

5 La première partie classique et difficilement évitable est consacrée aux conditions sociales et psychosociales des jeunes issus de l'immigration maghrébine en France, la seconde à la socialisation et transmission culturelle dans les familles, et à l'expression et aux stratégies et bricolages identitaires des jeunes appuyés sur la religion et la langue. Moins fréquente, cette partie, plus anthropologique, appuyée sur les données de l'enquête est très intéressante. La troisième partie présente l'école et la socialisation, y est analysée l'enquête auprès des enseignants français. Nombre de ceux-ci soulignent les avantages des ELCO même s'ils ne sont pas d'accord avec la forme qui leur est donnée. Il faut attendre la quatrième partie pour voir traitées et trop souvent de façon allusive les conditions d'une construction identitaire psychique favorable chez ces jeunes. Pour les jeunes ayant suivi les ELCO les images de soi positives sont plus fréquentes que les images de soi négatives; Avec le test «qui suis-je?» est examiné l'effet de la variable fréquention ou non des ELCO sur la formation identitaire et la question de l'appartenance : ceux qui suivent des ELCO donnent avec beaucoup de facilité des descriptions positives de leur groupe d'appartenance et présentent un sentiment très fort d'estime de soi. Chez les autres on relève souvent des oscillations entre deux pôles identitaires présentés comme négatifs avec une auto dépréciation de soi, ils valorisent peu la religion et la culture d'origine.

6 L'interprétation de A. Mohamed est que la langue d'origine enseignée très tôt préviendrait les crises identitaires occasionnées par un mauvais positionnement symbolique. Ce ne serait pas tant la distance entre le vécu socioculturel des jeunes et le monde scolaire et social qui serait en cause que la hiérarchisation opérée par le système social, la domination socioculturelle c'est-à-dire les effets désorganisateurs psychiques de la prise de conscience d'appartenir à un groupe défavorisé, les contradictions et paradoxes liés à l'assimilation au groupe majoritaire se marquent dans l'image de soi. Ainsi se trouvent confortées les données sociologiques issues du courant des recherches interethniques. 


\section{AUTEURS}

\section{GENEVIÈVE VERMÈS}

Professeur émérite, Institut Maghreb-Europe, Université de Paris 8, Genevieve.vermes @noos.fr 